\title{
Wat is wetenskap vandag?
}

\section{AJ Antonites}

\begin{abstract}
What is science today?

In this essay an attempt is made to answer the question as to what contemporary science is, by looking at science's main task, namely the sistematic methodical search for the truth. In this respect a cognitive model, which issued from radical change in recent science, is explicated: Attention is paid to a plural truth constitution of different sciences as well as to the problem of the existence and validity of different scientific paradigms in one and the same science. The importance as such, as well as the implications of radical reflection on science, is indicated.
\end{abstract}

\section{INLEIDEND}

Wanneer ' $n$ chemikus besig is met 'n eksperiment om ' $n$ chemiese reaksie te bewerkstellig, of 'n geoloog om die ontwikkeling van 'n bergreeks vas te stel, of ' $n$ historikus die redes vir ' $n$ bepaalde gebeure nagaan, of 'n wysgeer ' $n$ bepaalde denkrigting ondersoek, of ' $n$ teoloog met eksegese van ' $n$ perikoop besig is, of ' $n$ ingenieur die toepassing van 'n natuurwet in sy gebied ondersoek - weet al hierdie wetenskaplikes een ding seker, ondanks die uiteenlopende verskille in die aard van hulle onderskeie wetenskappe, en dit is dat hul besig is om wetenskap te beoefen en nie iets anders nie. Hulle is nie besig met sport, kuns of handel dryf nie, maar wetenskap. Almal is toegewyd besig met die oplos van probleme. Almal het wette en besef dat die kriteria van wetenskaplikheid vir hulle geld. Hoe is dit moontlik? Waar kom dit vandaan?

Op die chronologiese vraag sal 'n antwoord waarskynlik nie moontlik wees nie. Logies gesproke, blyk daar egter iets merkwaardig, naamlik dat mense onafhanklik van mekaar, sedert eeue gelede, gehoor gee aan die kriteria van wetenskaplikheid. Wysgerig gesproke, sou mens kon sê dat in soverre daar sprake is van menswees, daar 'n wekroep vir hom geld, en dit is om op ' $n$ bepaalde en wel teoretiese manier met sy wêreld om te gaan. Sonder dat hy eksplisiet besin het oor die wekroep van teoretiese waardes, wat objektief daar is, het hy gehoor gegee aan 
hierdie wekroep. Die uitkoms hiervan is wat ons noem wetenskap. Ons tref wetenskap aan in klassieke Griekeland, die Hellenistiese tydperk, Middeleeue, Renaissance, moderne en hedendaagse tydvakke.

'n Mens sou kon vra of ons by die Grieke van wetenskap kan praat. Wat nog te sê wat die Middeleeue betref. Twee sake moet mens toegee. Eerstens is die Middeleeue in vergelyking met die hedendaagse wetenskap darem heel anders: Ons hoor van geen wetenskaplike deurbrake, bevindinge ensovoorts nie. Tweedens is die Middeleeuse wetenskap baie eensydig en hoofsaaklik tot die teologie-wysbegeerte beperk. Tog openbaar die Middeleeuers 'n baie goeie kritiese ingesteldheid - hy probeer streng logies redeneer. Abelardus (1079-1142) stel selfs eksplisiet geformuleerde vereistes waaraan kennis behoort te voldoen. Kom ' $n$ mens by die Grieke dan vind ons dat Aristoteles die grondlegger was van metodes en gebiede wat in die hedendaagse wetenskap nie net gebruik en ontwikkel word nie, maar van kardinale belang is.

'n Mens sou dus kon aflei dat die mens dit as sinvol beleef om gehoor te gee aan die wekroep van teoretiese waardes wat hom aanspreek. Hoé die mens daaraan gehoor gee, verskil van tyd tot tyd, plek tot plek en wetenskaplike tot wetenskaplike.

\section{BETEKENIS VAN RADIKALE (WETFNSKAPSFILOSOFIESE) REFLEKSIE}

In enige wetenskap gebeur dit van tyd tot tyd dat nuwe insigte, teorieë, paradigmas, hipoteses, modelle en werkwyses aan die lig tree. Reeds dit vertel ons iets van wat wetenskap is, naamlik 'n dinamiese gebeure. So vind ons ' $n$ groot deurbraak en omwenteling in die geesteswetenskappe met die koms van die fenomenologies-hemeneutiese werkwyses; in die natuurwetenskappe weer die koms van die relatiwiteitsen kwantumteorie; in die teologiese wetenskappe die historiese kritiek en teksimmanente werkwyse.

In meeste gevalle, val hierdie verandering en ontwikkeling enersyds nie sommer uit die lug nie en andersyds spruit dit ook nie altyd voort uit 'n blote logiese voortgang van die wetenskap nie (die sg innerlike logika van wetenskaplike vooruitgang). Sodanige veranderings is dikwels radikaal van aard in ' $n$ bepaalde wetenskap en is die deurwerking van sulke veranderings in ' $n$ wetenskap dikwels ingrypend van aard. Daar kan meer as een rede hiervoor wees. Ons wil egter die volgende twee opmerkings maak. 
Eerstens val dit op dat veranderinge in 'n wetenskap wat nie oppervlakkig van aard is nie, dit wil sê min of meer radikaal, gewoonlik tot radikale en dus wysgerige refleksie lei. Wetenskaplikes begin om radikale vrae te vra oor die omvang, geldigheid, trefsekerheid en gronde ('radikaal' impliseer dat dit 'n wetenskap tot in sy grond raak) van hul vakke. Nuwe verwikkelinge word wysgerig geïnterpreteer. 'n Goeie voorbeeld by die natuurwetenskappe is die opkoms van die kwantumteorie en die onsekerheidsprinsipe by die mikro-fisika. Heisenberg, die formuleerder van die onsekerheidsprinsipe, die atoomfisikus, Niels Bohr en CF von Weiszacker het almal intensiewe wetenskapsfilosofiese refleksie en arbeid verrig. Die gevolg hiervan vir die wetenskapsfilosofie en terugwerkend weer op die wetenskappe, was tydig. Ons dink byvoorbeeld aan Niels Bohr se komplementariteitsprinsipe wat die wetenskaplike wêreldbeeld van perspektiwiteit (wat in die natuur- sowel as geesteswetenskappe vandag aanvaar word) mede help vorm het. Die omwenteling van die Newtonse tot die Einsteinse benadering in die fisika, beïnloed die fisikus-filosoof Thomas Kuhn se paradigma-filosofie. Die nawerking hiervan word vandag nog gevind in die wetenskapsfilosofie en talle vakwetenskappe. Die debat wat in wetenskapsfilosofiese kringe hierop gevolg het, gaan nog voort.

Tweedens gebeur dit van tyd tot tyd dat die omgekeerde ontwikkeling plaasvind. Dit beteken dat ingrypende wysgerige refleksie, insigte en omwentelinge lei tot betekenisvolle veranderinge in baie vakwetenskappe. Ten opsigte van die geesteswetenskappe is dit meer direk en ten opsigte van die natuurwetenskappe meer indirek. So het die filosofie van Ernst Mach vir Einstein in die ontwikkeling van sy denke beinvloed. Oneindig groter as Mach is die betekenis van die wiskundige-filosoof Rene Descartes (1596-1650). Descartes se filosofie rondom die res extensa en res cogitans word uiteindelik die wêreldbeeld waarmee die natuurwetenskappe gewerk het en wat hulle veronderstel het dwarsdeur die moderne tyd en vandag nog in die veld is. Hierdie wêreldbeeld behels die Cartesiaanse dualisme (Cartesiaans van Descartes). Die wysgerige besinning van Heisenberg en Bohr het hierdie wêreldbeeld mede help verander.

In die geesteswetenskappe het Husserl, Heidegger en Scheler 'n ingrypende wending in die filosofie gebring, bekend as die fenomenologie. Husserl het geen spesifieke vakwetenskaphke tegnieke uitgewerk nie, maar 'n basiese wysgerige benadering en werkwyse daargestel. Dit het deurgesuur na talle geesteswetenskappe soos die geskiedenis, psigologie, sosiologie en opvoedkunde. Hierdie wetenskappe het 
elkeen op sy eie manier en vanuit sy eie perspektief 'n vakwetenskaplike metode daarvan gemaak en ook aansluitende tegnieke ontwikkel. 'n Mens sou dus hierdie radikale refleksie as een van die redes noem vir omwentelinge en veranderinge in 'n vakwetenskap.

Hierdie veranderinge laat ons die vraag vra: Kom die wetenskap dan nie by die waarheid uit nie? Het dit nie gearriveer nie? Kan dit arriveer? Dit roep die belangrike kwessie van die waarheid op. Die vraag, 'wat is wetenskap?', impliseer juis die waarheidsvraag. Die 'wete' van wetenskap dui op kennis. (Vgl die wissen in die Duitse Wissenschaft.) Praat jy van kennis, praat jy van waarheid. Die wetenskap wil die waarheid ken.

\section{WAARHEID EN OBJEKTIWITEIT BY DIE WETENSKAP: EEN WAARHEID OF VELE?}

Ons sal dikwels kry dat mense buite die wetenskap tot ' $n$ ware insig kom. Hulle praat dan die waarheid. Menigmaal het ' $n$ boer al gesê dat koolstof goed is vir beeste wat siek is as gevolg van tulpe wat hul geëet het. Dit blyk korrek te wees. Die boer het dit nie wetenskaplik vasgestel nie, maar hy praat die waarheid. Ons vind dat sekere Griekse gedigte menslike gevoelens en emosies baie waar beskryf, asook wat die gebruik van slawe te Mycenae betref. Ook dit is nie 'n geesteswetenskaplike insig nie. Dis nogtans waar. Hoekom sou waarheid dan juis so prominent figureer by die vraag na wat die wetenskap is?

Anders as by die boer of die digter gaan dit in die wetenskap nie net by uitnemendheid om die waarheid nie, maar dit gaan om ' $n$ metodiese oopdek of soeke na waarheid. Anders as die digter of boer wat geen sodanige rekenskap gee of hoef te gee nie, want dit gaan vir hulle om 'n heel ander omgang met hul wêreld, moet die wetenskaplike kan rekenskap gee van sy meta hodos, van die weg waarlangs hy geloop het om by hierdie insig te kom. Hodos dui op die pad of weg. Meta sê dat om by ' $n$ bepaalde doel uit te kom, jy 'n geskikte en nie onvanpaste pad moet loop nie.

Die wetenskap is ' $n$ gesistimatiseerde metodiese manier om by die waarheid uit te kom. Die waarheid? Sou ons van die waarheid as een waarheid kan praat? Elke wetenskap ondersoek 'n bepaalde deel van die werklikheid, elkeen het te doen met 'n synde van die syn. Dis wat die begrip 'vak' by vakwetenskap wil sê, naamlik dat elke vakwetenskap met ' $n$ vakkie of deeltjie van die wêreld te doen het. Ons het 
met een en dieselfde wêreld te doen. Impliseer dit nie ook sy korrelaat, naamlik een waarheid nie?

In die Cartesiaans-georiënteerde natuurwetenskaplike denke, veral in sy sterkste uitloper, naamlik die positivisme, wat sedert die dertigerjare 'n opbloei beleef het, geld dat die werklikheid een groot synstotaliteit is. Laasgenoemde is ' $n$ op-sigself-staande-wêreld. In terme van die Cartesiaanse dualisme staan daar teenoor hierdie objektivistiese wêreld 'n suiwere bewussyn (van die wetenskaplike) wat hierdie wêreld op 'n objektiewe wyse ken soos wat hy in homself is. Laasgenoemde het belangrike kenteoretiese implikasies: Dit beteken dat as jy die wêreld kan ken soos wat hy in sigself is, dan besit hy (die wêreld) 'n rasionaliteit wat volledig deursigtig is en so geken kan word; dit beteken dat kennis daarvan neerkom op ' $n$ weerspieëling van so ' $n$ volkome verklaarbare wêreld. As dit 'n weerspieëling behels, beteken dit weer dat jou kennis ook die waarheid oor die wêreld is - al wat verder kan gebeur, is dat daar 'n kontinue, kumulatiewe vermeerdering van kennis kan wees. Dié kumulatiewe waarheidsvisie is tot vandag die siening van die logiese empirisme en logiese positivisme. Nuwe teorieë omvat volgens hierdie rigtings ouer teorieë. Wat as waarheid bevind word, is die waarheid, omdat dit induktivisties-empiristies verifieerbaar en gerugsteun is. Hoewel daar verskillende wetenskappe is, geld dit dat hulle almal saam één objektiewe sintese vorm, waar mens dan één objektiewe waarheid het. Die kriteria wat objektiwiteit bepaal, het die empirisme en kwantitatiewe as inhoud. Wat nie empiristies-kwantitatief is nie, is nie objektief nie. In werklikheid kom dit neer op een enkele wetenskap wat met één enkele metode op 'n volkome rasionele manier te ken is: Én objektivistiese wêreld wat ooplê en in één enkele wetenskap objektief te ken is. Dit impliseer 'n metodemonisme en wel dié van die fisika en chemie of liewers 'n bepaalde (positivistiese) benadering daarvan. Ook die geesteswetenskappe word 'n sosio-fisika.

As ons praat van 'n suiwer bewussyn wat 'n objektivistiese wêreld kan weerspieël, dan volg dit dat die subjek- en objek-pool geskei is, elkeen onafhanklik op sigself (kenteoretiese dualisme). Dit volg ook dat die mens, met ander woorde subjektiwiteit, geëlimineer is uit die wêreld, want die wêreld is mos 'objektief' daar. Die menslike wetenskap as subjek is min of meer ' $n$ passiewe toeskouer van die wêreld. Hoogstens registreer en akkumuleer hy feite.

Hierdie kognitiewe model van die wetenskap het die wetenskap grootliks aan bande gelê, verarm en tot reaksie gelei in die vorm van skeptisisme. Waar die eensydige kognitiewe model 'n te dogmatistiese 
waarheidsvisie gehad het, het die pendulum na die ander uiterste beweeg, naamlik dié van selfs radikale skeptisisme. Ons dink aan die 'anargie'-model van Feyerabend in die hedendaagse tyd, asook die minder radikaal-skeptiese, maar wel relatiwistiese denke by Thomas Kuhn. (Kuhn en Feyerabend is albei natuurwetenskaplike filosowe.) Alleen radikale deurdenking, soos wat onder andere in genoemde reaksie plaasgevind het, sou 'n beter kognitiewe model tot gevolg kon hê. Naas die bogenoemde omwenteling in natuurwetenskaplike kringe in die huidige periode, vind daar ook in dieselfde tydvak' $n$ ander radikale deurdenking plaas en wel by die wysbegeerte. Wat merkwaardig is, is dat hierdie twee omwentelinge heeltemal onafhanklik van mekaar plaasgevind het, maar dat die uitkoms daarvan ' $n$ kognitiewe model vir die wetenskap was, asook 'n nuwe wetenskaplike wêreldbeeld, wat groot ooreenkoms met mekaar vertoon. Ten opsigte van die natuurwetenskappe is dit eintlik twee omwentelinge: Eerstens is dit die revolusionêre verandering en refleksie van die kwantum-teorie, onsekerheidsprinsipe en relatiwiteitsteorie. Tweedens behels Popper, Kuhn, Lakatos, Feyerabend en Toulmin se anti-induktiwistiese en antipositiwistiese konstruksies ' $n$ omwenteling in natuurwetenskaplike denke. By die wysbegeerte is dit die fenomenologies-hermeneutiese omwenteling.

Die nuwe kognitiewe model het die oue verbygegaan. Die verbygaan is egter logies en nie chronologies nie, aangesien die ou model nog in die veld is. Die afgelope twee jaar is pogings aangewend tot ' $n$ meer gesofistikeerde uitwerk van die ou model. So kan ons die poging noem van onder andere Solomon.

Een van die belangrikste insigte van die nuwe kognitiewe model is dat wetenskappe nie met een wêreld te doen het nie, maar met vele wêrelde omdat die mens veelsydig gesitueerd is. Die wetenskap word gevoed en sal steeds gevoed word deur 'n oorspronklike situasie, waar die mens nie passief teenoor gegewe reële objekte staan nie, maar in 'n aksie van singewing. Oorspronklik is die menslike subjek dus primêr geen passiewe 'innemer' van louter waarnemings of gegewens nie elke waarneming geskied vanuit ' $n$ bepaalde standpunt en onder 'n bepaalde gesigspunt of konteks wat te doen het met elke mens se unieke konkrete gesitueerdheid. Maar dit kleur elke waarneming. Daar is sprake van perspektiwiteit. Te midde van die perspektiwiteit, is daar tussen subjek en objek 'n dialektiese verhouding waar sowel subjek- as objek-pool mede-betrokke is. In hierdie ontmoeting tussen mens en wêreld, bloei sin op. As dit so is, dan beteken dit heel konkreet dat te 
midde van 'n gemeenskaplike leefwêreld, daar vele wêrelde is. So is daar vir elke mens sy eie wêreld wat vir hom oorspronklik is. Maar omdat elkeen in sy eie wêreld veelsydig gesitueerd is, is daar ook by elkeen veelheid van sin.

Die wetenskap is nou (volgens die nuwe kognitiewe model) ' $n$ besondere vergestalting van bogenoemde. As dit so is, dan is wetenskaplike kennis 'n besondere ontmoeting met jou wêreld, waarin die geldigheid van teoretiese waardes meespreek en wetenskaplike sin opbloei. Gevolglik bloei besondere sinvelde op en dit word die veld van wetenskaplike ondersoek. In die lig van wat ons tot dusver gesê het, beteken dit dat die wetenskaplik-teoretiese ontmoeting met die wêreld eweneens 'n veelsydige gestalte gaan openbaar. Anders gesê: Die sinvelde wat na vore tree, word getematiseer (tot tema gemaak, dus tot objeksgebied gemaak). Hierdie tematisering geskied dan in baie verskillende vorme sodat daar soveel wetenskappe gaan wees as wat daar wyses is waarop die dinge (objekte) hulle in verskillende tematiserings laat konstitueer. In hierdie dialoog of ontmoeting waarby die subjek nie meer passief net feite registreer nie, maar tesame met die objek aktief is, word ' $n$ bepaalde vakwetenskaplik-tematiese veld afgebaken. Ons kan sê dit word 'uitgehaal' of geabstraheer uit sy heel oorspronklike veld. Dit beteken dat ' $n$ bepaalde aspek van 'n saak belig word. Volgens hierdie kenmodel het ons dus nie meer met 'n objektiwistiese wêreld met sy objekte te doen nie, maar 'objektief' lê by sowel objek as subjek; meer presies: in die dialoogrelasie tussen die subjek- en objekpool. So ' $n$ afgebakende sinveld van ' $n$ bepaalde wetenskap, kan alleen ontsluit word deur 'n wetenskaplike metode, tegnieke, werkwyse, begripsapparatuur en taal wat korrelatief tot die objek is.

Subjek en objek is nie meer twee op sigself algeheel onafhanklike wêrelde nie. Subjek-pool en objek-pool bly steeds belangrik, want anders kan die kenrelasie oorswaai na 'n subjektivisme. Nou is die wêreld deurtrek met subjektiwiteit en andersom. Kennis van die wêreld is kennis van 'n menslike wêreld en die kennende subjek is wêreld-gesitueerd. Sprake van 'n één wêreld is daar nie meer nie. Die korrelaat hiervan is dat die kennis van die verskillende wetenskappe nie 'n homogene eenheid vorm nie. Om te praat van ' $n$ sintese van al hierdie kennis is nie moontlik nie, want daar is nie meer éen waarheid nie. In elke wetenskaplike singebied geld waarheid onder voorwaardes wat konstituerend van daardie vakgebied is. Elke wetenskap het sy eie wêreld. Vir byvoorbeeld die eksegeties-teologiese wetenskappe geld die wêreld van die teks. Teologie is geen herhaling van die teks nie 
(geen blote weerspieëling nie), maar ook hier is daar dialoog en ontmoeting tussen subjek en objek. Hier is die subjek in die laaste instansie God. Waarheid is relasionele waarheid. Ook hier is waarheid nie buite die mens moontlik nie (kyk Velthuysen 1985).

Die nuwe kognitiewe model word verder gekenmerk deur die klem op probleemstelling en probleemformulering. Die hedendaagse wetenskap het 'n probleemgerigte houding. Uiteraard speel die subjekpool hier 'n meer belangrike rol. HG Gadamer wys in sy opstel 'Practical philosophy as a model of the human sciences' daarop dat 'n historiese feit in die hedendaagse wetenskap van die geskiedenis nie iets is wat bloot werklik gebeur het nie, maar iets wat werklik gebeur het op so ' $n$ manier dat dit besondere betekenis het vir 'n historiese vraag. In die geskiedeniswetenskap (en so ook ander geesteswetenskappe) gaan dit ook nie om 'n samebondeling van feitlike gegewens nie. Die doel is selfs nie eens die gegewens nie. Dit is slegs middele tot ' $n$ doel, naamlik die konstruksie van leefwêrelde en menslike handelinge (kyk Dreyer 1974). Hier is wetenskaplike kennis geen hiaatlose kontinuïteit nie - daar is diskontinuiteite, hiate en onsekerhede. Probleemformulering is aan die orde van die dag. Ons vind verskillende soorte wetenskaplike verklarings, ook binne een en dieselfde wetenskap, omdat ons verskillende soorte vrae vra. Verskillende teorieë is 'n gevolg hiervan wat weer tot verdere probleemstelling lei. Dat probleemstelling soos pas genoem, die rol van die subjek beklemtoon en ons derhalwe by die wetenskap nie meer die objektivisme het waar die objek-pool hoofsaaklik alleen praat en die wetenskap objek-bepaald is nie, het ons in die hedendaagse wetenskap die situasie waar ons vind dat uiteenlopend verskillende wetenskappe dieselfde objek ondersoek. Dis dieselfde objek, maar verskillende vrae word daaroor gevra; verskillende aspekte van die objek word uitgelig. So byvoorbeeld kry ons dat spierweefsel deur verskillende wetenskappe tot objek in hul onderskeie sinvelde gekonstitueer word. Spierweefsel word onder meer ondersoek deur elektrofisiologie, biochemie en termodinamika. Die groter voorrang van subjektiwiteit in die wetenskap-kenteoretiese relasie, word ook treffend geillustreer in die atoomfisika: Die ontdekkings van Rutherford en Thompson was nie die uitkoms van eksperimenteel-empiriese toetsing ('objektiewe'-data) nie, maar vanweë subjektief-teoretiese konstruksies en kategorieë. Einstein se relatiwiteitsteorie vervang dié van Newton ook nie as gevolg van die 'objektief-waargenome feite' nie, maar is 'n primêr teoretiese konstruksie. Dit staan gevolglik bekend as 'n 'hoë-vlak'-teorie. Dis probleme wat die mens beweeg om 
aandag aan sake in 'n area te gee. Navorsing ontstaan as iets problematies oor sake in 'n area ontstaan.

Langs heel ander weë as die fenomenologie het die natuurwetenskappe die afgelope dekades tot baie soortgelyke resultate met betrekking tot die nuwe kognitiewe model gekom. In die mikrofisika is tot die insig gekom dat partikels nie meer as objektief-vasstaande objekte geken kan word nie (die kwantum-teorie en onsekerheidsprinsipe). Werner von Heisenberg en ook Niels Bohr sê dat die wetenskaplike subjek nie meer 'n passiewe registreerder van objektivistiese feite is nie, maar ' $n$ medespeler. Die wetenskaplike ontdek in die wêreld wat hy ondersoek niemand anders as homself nie! Dis nie meer louter weergawe of weerspieëling nie, maar-'n-deur-die-mens-ondervraagdenatuur. By Popper verkry teorie voorrang bo die empiriese: Daar is geen louter onafhanklike empiriese feite nie, maar feite is altyd en alreeds geïnterpreteerde (deur teorie as 'n subjektief-menslike skepping) feite. Daar is geen bruta facta in die natuurwetenskappe nie. Teorie en empirie is wisselwerkend tot mekaar verbind en is nooit los te maak nie. Die positivistiese verifikasie-kriterium asook induktivisme word afgewys.

\section{PERSPEKTIWITEIT VAN WAARHEID EN HERMENEUTIESE DIMENSIE}

Ons het reeds gesien dat ' $n$ bepaalde vakwetenskap self 'n perspektief op die werklikheid met sy eie sinveld het. As al hierdie dinge nou so is, dan is dit logies dat binne een en dieselfde wetenskap die veelheid van menslike konkrete gesitueerdheid ook tot uiting gaan kom. Daar is nie net ' $n$ rykdom van verskeie wetenskappe nie, maar binne dieselfde wetenskap eweneens 'n verskeidenheid van perspektiewe op dieselfde saak. Die begrip perspektief (van Latyns perspicere $=$ om deur te sien, aandagtig te kyk, ondersoek, verken) sê dat geen mens bloot waarneem nie, maar op ' $n$ besondere manier, by 'n besondere situasie vir 'n besondere doel. Niels Bohr se komplementariteitsgedagte lui dat geen enkele wetenskaplike beeld van die wêreld die werklikheid in al sy fasette kan omvat nie. 'n Pluraliteit van beelde of perspektiewe is onvermydelik en selfs nodig.

In feite kry ons binne die natuur-, geestes- en teologiese wetenskappe verskillende perspektiewe in die vorm van paradigmas, teorieë en ander kontekste. In die natuurwetenskappe is daar onder andere die Newtonse, Einsteinse en kwantum-paradigmas. In die 
geesteswetenskappe is daar die Hempeliaanse, fenomenologiese en funksionalistiese perspektiewe; in die teologies-eksegetiese wetenskappe die historiese kritiek en teksimmanente teorieë. Hierdie paradigmas of teorieë ('n teorie is 'n raamwerk van verklaring of interpretasie en nie iets voorlopigs soos dikwels populêr gemeen word nie) is kontekste of perspektiewe. Ons vind dan dat sake binne die wetenskaplike dialoogsituasie vanuit 'n perspektief verskillend gesien kan word. Hier kom 'n hermeneutiese dimensie ter sprake. Gadamer stel tereg dat ' $n$ feit alleen ' $n$ feit is met betrekking tot betekenisvolheid: Dis nie die feit nie, maar die konteks wat die betekenis van 'n feit definieer. Feit het betekenis vir 'n bepaalde wetenskaplike vraag wat weer moontlik word vanweë 'n bepaalde teorie.

Hierdie hermeneutiese dimensie is nie net beperk tot die geesteswetenskappe nie. Dis nie so dat natuurwetenskappe te doen het met eksperimentele feite, terwyl die geesteswetenskappe te doen het met geïnterpreteerde feite nie. Die hermeneutiese dimensie geld ook in die hedendaagse natuurwetenskappe: Hier is dit eweneens die konteks wat iets betekenisvol maak. Dis nie die blote vermeerdering en uitbreiding van eksperimentele data wat vooruitgang konstitueer nie, maar juis die hermeneutiese dimensie! Dis die probleem, die vraag, wat 'feite' konsitueer (kyk Dreyer 1974).

So byvoorbeeld gee die Ptolemaise en Newtonse teorieë dikwels aanleiding tot verskillende indelings van dieselfde objekte. Vanuit die een teorie se dimensie is sekere sake relevant en soms van kardinale belang, terwyl dit in die ander teorie nie juis van belang is nie en soms heeltemal irrelevant. In die Newtonse meganiese teorie is ruimte en tyd twee verskillende kriteria, maar nie in die relatiwiteitsteorie nie. 'n Betreklik onlangse voorbeeld illustreer hoedat twee verskillende teorieë in dieselfde wetenskap aanleiding gee tot verskillende probleemstellings en dan weer tot die verskynsel dat daar glad nie 'n probleem ervaar word nie. By die wetenskap van die astronomie het Australiese sterrekundiges waarnemings gemaak van die verafgeleë ster Quasar 3 C 273. Radio-teleskope het aangedui dat 'n bondel van materie wegbeweeg het vanaf die hoofliggaam van die Quasar. Waarnemings is gemaak tydens ' $n$ periode van drie jaar. Dit het geblyk dat die bondel omtrent 25 ligjare in die periode beweeg het, wat beteken dat die materie se snelheid die snelheid van lig aansienlik moes oorskry het.

Volgens die ouer Newtonse teorie se interpretasie van bogenoemde waarnemings, is daar geen probleem hiermee rie. Vanuit die perspektief van die jongere relatiwiteitsteorie is hierdie waarneming 'n enorme 
probleem - tewens die waarnemings kan nie wees nie. Dis nie veronderstel om voor te kom nie, want volgens die relatiwiteitsteorie kan niks vinniger beweeg as die snelheid van lig nie (kyk Brown 1977). Die belangrikheid van die hermeneutiese dimensie blyk ook daarin dat die oplossing van die meningsverskil tussen die twee teorieë, nie geleë is in 'n verdere noukeurige ondersoek van die data of feite nie. Bruta facta sou nie die probleem oplos nie.

In die teologies-eksegetiese wetenskappe vind ons dat daar gekom is tot die insig dat daar in die evangelies teenstrydige vertellinge is ten opsigte van die detail oor ruimte of tyd met betrekking tot ' $n$ bepaalde gebeure. Lukas en Matteus byvoorbeeld se vertel van dieselfde aangeleentheid weerspreek mekaar dikwels. Volgens 'n ouer teologiese teorie is die teenstrydighede ' $n$ probleem. Vir jonger teologiese teorieë is dieselfde saak nie veel van 'n probleem nie. Weer eens is dit die hermeneutiese dimensies van die paradigma - perspektief wat probleemstelling bepaal en nie bruta facta nie. Elke perspektief het sy eie veronderstellings, basiese kategorieë en interpretasies.

Die historikus-filosoof RG Collingwood het reeds in die laat dertigerjare gevra by watter geleenthede, en deur watter gebeure word een stel fundamentele konsepte of konstellasies van absolute veronderstellings deur ' $n$ ander vervang? Hierop antwoord die fisikus-filosoof TS Kuhn in 1962 met sy The structure of scientific revolutions (kyk Toulmin 1972). Kuhn meen dat verskillende paradigmas mekaar opvolg in die tyd, dat die breuk en verskil tussen twee paradigmas so fundamenteel diskontinu is, dat kommunikasie tussen die twee buite die kwessie is, omdat elkeen in verskillende wêrelde leef, byvoorbeeld die Newtonse en Einsteinse teorieë. Toulmin, weer, meen dat die diskontinuïteit nie so revolusionêr-fundamenteel is nie.

Veel eerder lyk dit of ons die bestaan van 'n veelheid van paradigmas, teorieë, perspektiewe binne dieselfde wetenskap moet sien as voortspruitend uit wat ons vantevore oor tematisering, dialoog en gesitueerdheid gesê het. Dit is omdat ons mense is. Aan die een kant het die positivistiese wêreldbeeld van één wêreld, één waarheid, één wetenskap prinsipieel en in feite verbygegaan. Aan die ander kant weer beteken dit egter nie dat verskillende perspektiewe en verskillende wetenskappe in 'n monadiese eensaamheidswêreld leef nie. Wetenskaplike gesprek, kritiek, kruisbestuiwing en korreksie is nie net wenslik nie, maar selfs noodsaaklik omdat geen perspektief gearriveer het nie. Geen mens, geen wetenskaplike gaan die waarheid finaal inpalm nie. Perspektiewe is aanvullend tot mekaar. Dit beteken nie dat 
'n sintese as mikpunt gestel moet word nie, want dan val ons weer terug op die positivistiese waarheidsideaal. Martin (1965) het gelyk wanneer hy sê dat daar in 'n wetenskap kontradiksie is, maar nie alles is en kan kontradiksies wees nie. Ons kan dit so formuleer: Algehele eenstemmigheid in alles is sinneloos; algehele verskil in alles is ewe sinneloos.

Juis hierin is die dinamo van die dinamiek van die wetenskap geleë.

\section{Literatuurverwysings}

BROWN, HI 1977. A functional analysis of scientific theories. Zeitschrift fur Allgemeine Wissenschaftstheorie 8.

DREYER, PS 1974. Inleiding to die filosofie van die geskiedenis. Kaapstad: HAUM.

MARTIN, G 1965. Allgemeine Metaphysik: Ihre Probleme und ihre Methode. Berlin: De Gruyter.

TOULMIN, S 1972. Human understanding, Volume I: General introduction and Part I. Oxford: Clarendon Press.

VELTHUYSEN, GC 1985. Die betekenis van die relasionele waarheidsbegrip vir die Skrifbeskouing. HTS 41, 108-113. 